\begin{tabular}{lll}
\hline Bentham OPEN & The Open Hypertension Journal \\
\hline & Content list available at: www.benthamopen.com/TOHYPERJ/ & DOI: $10.2174 / 1876526201810010008$ \\
\hline
\end{tabular}

RESEARCH ARTICLE

\title{
Features of the Lipid Profile in Patients with Arterial Hypertension and Cardiovascular Diseases According to Smoking Status
}

\author{
Oleg V. Gaisenok ${ }^{1,2}$, Sergey Yu. Martsevich ${ }^{2}$ and Marina V. Leonova, \\ ${ }^{I}$ Department of Cardiology, United Hospital with outpatient Department, Moscow, Russia \\ ${ }^{2}$ Department of Preventive Pharmacotherapy, National Research Center for Preventive Medicine, Moscow, Russia \\ ${ }^{3}$ Department of Clinical Pharmacology, Russian National Research Medical University N.I. Pirogov, Russia
}

Received: December 18, 2017

Revised: March 10, 2018

Accepted: March 19, 2018

\begin{abstract}
:
Introduction:

Smoking is a risk factor for cardiovascular diseases. The direct influence of smoking status on the lipid profile was highlighted in patients with arterial hypertension and associated cardiovascular disease.
\end{abstract}

\section{Objective:}

We aimed to evaluate lipid profile among patients related to smoking status in a registry-based cohort study.

\section{Methods:}

The data of registry of National Research Center of Preventive Medicine were conducted. Patients filled in the special questionnaire in order to identify their smoking status, statins therapy.

\section{Results:}

274 patients were included; main nosologic disease was arterial hypertension (230 patients), $14.8 \%$ were smokers, $62.9 \%$ nonsmokers, and $22.2 \%$ past-smokers. The rank analysis of variations by Kruskal-Wallis $(\mathrm{H})$ test for multiple comparisons between groups revealed significant differences in lipid levels for patients according to smoking status: total cholesterol $\mathrm{H}(2, \mathrm{n}=234)=9.119$, $p=0.0105$; LDL-cholesterol H $(2, \mathrm{n}=225)=6.2615, p=0.0437$; triglycerides $\mathrm{H}(2, \mathrm{n}=216)=9.8485, p=0.0073$; these indicators of lipid profile among non-smoking patients were lower than among smokers, these indices among past-smokers were lower than among smokers. The absence of statistically significant differences between groups was confirmed in statin therapy $\left(\chi^{2}=3.169, \mathrm{df}=4\right.$, $p=0.529)$. Logistic regression analysis was conducted to identify factors that influence achievement target lipid levels. Only 2 statistically significant signs were identified in this model: smoking (OR $0.1 ; 95 \% \mathrm{CI}[0.13 ; 4.87] ; p=0.03)$ and statin therapy (OR $8.2 ; 95 \%$ CI $[-3.6 ;-, 078] ; p=0.002)$.

\section{Conclusion:}

Significantly higher lipid levels have been observed in smokers compared to non-smokers in patients with arterial hypertension and associated cardiovascular disease. Smoking is a great factor disincentive to achieve target lipid levels.

Keywords: Arterial hypertension, Cardiovascular diseases, Lipid-lowering therapy, Statins, Cholesterol, Low density lipoprotein cholesterol, Smoking status, Registry.

\footnotetext{
* Corresponding authorAddress correspondence to this author at the Russian National Research Medical University N.I. Pirogov, Ostrovityanov str. 1, Moscow, Russia, 117997; Tel: +79153204379; E-mail: anti23@mail.ru
} 


\section{INTRODUCTION}

Smoking is one of the most common risk factors of cardiovascular disease and complications [1, 2].

Effects of smoking on the cardiovascular system are multifaceted and mediated by different mechanisms. Smoking causes harmful hemodynamic effects: increased blood pressure and promotes the development of arterial hypertension, impaired renal function and reduced glomerular filtration, the development of kidney failure. These effects are mediated by the development of oxidative stress and inflammation under smoking, which damages the vascular wall and leads to endothelial dysfunction. In addition, smoking causes a number of adverse metabolic effects: potentiates the development of insulin resistance and impaired metabolism of lipids, which leads to damage to the vascular wall and increased arterial stiffness.

Arterial hypertension and hyperlipidemia predicted cardiovascular complications such as myocardial infarction and stroke. The effect of total cholesterol (TCH) and low-density lipoprotein cholesterol (LDL-C) levels on carotid intimamedia thickness was studied in previous works and the differences in the dependence on smoking status were confirmed [3]. It was expected that different mechanisms were involved in atherogenesis in LDL according to smoking status [4, $5]$.

Current international recommendations indicate the need for correction of lipid metabolism to achieve the target levels of TCH, LDL-C, high-density lipoprotein cholesterol (HDL-C) and triglycerides (TG) [6 - 8], since lipid factors are fundamental in the formation of atherosclerotic vascular lesions, which lead to the appearance of associated cardiovascular diseases. At the same time, smoking is a factor that leads to the progression of the disease and is a modifiable risk factor. Therefore, it seems that there is an association of arterial hypertension, hyperlipidemia and smoking exert synergistic effects on arterial stiffness, atherogenesis and progression of cardiovascular diseases [7 - 10].

Many previously published studies demonstrate the higher values of cholesterol and LDL-C in the group of smokers compared to non-smokers [5, 10 - 12]. However, this problem has not been detailed in patients with arterial hypertension especially in the Russian population, and non data of the role smoking status on effectiveness lipidlowering therapy.

The aim of this study was to evaluate lipid profile of patients with cardiovascular diseases related to the smoking status in a cohort of Russian patients with arterial hypertension and cardiovascular diseases, based on registry rules.

\section{MATERIAL AND METHODS}

PROFILE is a registry of patients of one of the divisions of the National Research Center for Preventive Medicine (NRCPM), the department of preventive pharmacotherapy. The PROFILE registry sequentially includes all patients with cardiovascular diseases who applied to the department for a consultation. The present study included patients with arterial hypertension and assessment clinical conditions (such as coronary artery disease, diabetus mellitus) who applied to the department and formed the first part of PROFILE registry, answering a specially developed questionnaire in order to identify their current smoking status (smoking, non-smoking, gave up smoking), intake of lipid-lowering drugs of statins group (taking them regularly, taking them irregularly, not taking these drugs), job stress (yes, no), physical activity (regular, irregular), diet (comply, do not comply with it), education level (presence of higher education, lack of it), alcohol consumption (do not use, less often 1 time per week, more often 1 time a week). Questionnaire and registration card were developed by the researchers. The patient filled in a questionnaire; a physician filled in a registration card. Anamnestic, anthropometric and nosological data, results of clinical, laboratory and instrumental studies and survey data of patients were recorded in the registration card. All patients signed informed consent to participate in the study, and the questionnaire was approved by the Independent Ethics Committee of NRCPM. Blood tests for cholesterol and its fractions were carried out in the laboratory of NRCPM on the same day of a patient's visit.

Statistical data processing was performed using the software package Statistica 6.0 (Statsoft Inc). Data on groups of signs are presented as median and interquartile range or as real numbers and the proportion (\%) of the total number of patients. $\chi^{2}$ criterion was used for comparison groups on the basis of qualitative character. Rank analysis of variations by Kruskal-Wallis test was used for multiple comparisons of groups (three or more) of quantitative character. Dunn criterion was used to assess intergroup differences. Logistic regression was selected for multivariate analysis. The contribution of different factors in achieving target lipid levels, the odds ratio obtaining this result and their confidence intervals were determined by this method. Differences were considered statistically significant when $p<0.05$. 


\section{RESULT}

The present study included 274 patients who sequentially applied to the department of preventive pharmacotherapy. The baseline clinical and nosological characteristics of the patients are shown in Table 1. The main nosologic disease was arterial hypertension (230 patients), among them $14.8 \%$ were smokers.

Table 1. Baseline clinical and nosological characteristics of study group.

\begin{tabular}{|c|c|}
\hline Sign & Proportion of Patients \\
\hline Age (years) & $64.0[57.0 ; 72.0]$ \\
\hline Male gender & $135(49.3 \%)$ \\
\hline Body mass index (BMI, $\left.\mathrm{kg} / \mathrm{m}^{2}\right)$ & $28.7[25.4 ; 31.3]$ \\
\hline Blood pressure (mm Hg) & - \\
\hline $\begin{array}{c}\text { Smoking status: } \\
\text { Smokers } \\
\text { Non-smokers } \\
\text { Past-smokers }\end{array}$ & $\begin{array}{l}40(14.8 \%) \\
170(62.9 \%) \\
60(22.2 \%)\end{array}$ \\
\hline Arterial hypertension & $230(83.9 \%)$ \\
\hline $\begin{array}{c}\text { Coronary artery disease } \\
\text { including: }\end{array}$ & $85(31.0 \%)$ \\
\hline - history of myocardial infarction & $47(17.1 \%)$ \\
\hline - history of interventional procedures & $81(29.5 \%)$ \\
\hline History of stroke & $19(6.9 \%)$ \\
\hline Diabetes mellitus & $43(15.7 \%)$ \\
\hline $\begin{array}{l}\text { Hypercholesterolemia at baseline }>5.0 \\
\text { Hypercholesterolemia in the present time }>5.0 \\
\text { Hypercholesterolemia in the present time }>4.5\end{array}$ & $\begin{array}{l}266(97.0 \%) \\
113(41.2 \%) \\
153(55.8 \%)\end{array}$ \\
\hline
\end{tabular}

The patients were divided into 3 main groups according to their current smoking status: (1) those who smoke (smokers), (2) those who do not smoke (who never smoked) (non-smokers), and (3) those who gave up smoking (pastsmokers). The comparison of these groups by lipid spectrum is presented in Table 2.

Table 2. Comparison of groups by lipid spectrum.

\begin{tabular}{|c|c|c|c|c|c|c|c|}
\hline \multirow[b]{2}{*}{-} & \multicolumn{2}{|c|}{ Smokers } & \multicolumn{2}{|c|}{ Non-Smokers } & \multicolumn{2}{|c|}{ Past-Smokers } & \multirow[b]{2}{*}{$p$-value } \\
\hline & $\begin{array}{c}\text { Mean } \\
\text { (Std.Dev.) }\end{array}$ & $\begin{array}{c}\text { Median } \\
\text { [Lower; Upper] }\end{array}$ & $\begin{array}{c}\text { Mean } \\
\text { (Std.Dev.) }\end{array}$ & $\begin{array}{c}\text { Median } \\
\text { [Lower; Upper] }\end{array}$ & $\begin{array}{c}\text { Mean } \\
\text { (Std.Dev.) }\end{array}$ & $\begin{array}{c}\text { Median } \\
\text { [Lower; Upper] }\end{array}$ & \\
\hline $\mathrm{TCH}$ & $5.66(1.14)$ & $5.50[5.00 ; 6.09]$ & $4.92(1.16)$ & $4.80[4.00 ; 5.80]$ & $5.16(1.49)$ & $4.70[4.05 ; 6.10]$ & 0.0105 \\
\hline LDL-C & $3.59(1.01)$ & $3.69[2.85 ; 4.34]$ & $3.09(1.14)$ & $3.00[2.22 ; 3.69]$ & $3.15(1.21)$ & $2.77[2.39 ; 3.89]$ & 0.0437 \\
\hline HDL-C & $1.32(1.17)$ & $1.17[0.99 ; 1.31]$ & $1.24(0.30)$ & $1.20[1.03 ; 1.41]$ & $1.21(0.25)$ & $1.22[1.03 ; 1.35]$ & 0.3475 \\
\hline TG & $1.91(1.01)$ & $1.68[0.97 ; 2.37]$ & $1.38(1.07)$ & $1.18[0.87 ; 1.59]$ & $1.69(1.34)$ & $1.31[0.99 ; 1.79]$ & 0.0073 \\
\hline
\end{tabular}

TCH - total cholesterol; LDL-C - low-density lipoprotein cholesterol; HDL-C - high-density lipoprotein cholesterol; TG - triglycerides.

Differences in the level of total cholesterol, low-density lipoprotein cholesterol and triglycerides were observed between the groups: these indicators of lipid profile among non-smoking patients were lower than among those who gave up smoking while these indices among past-smokers were lower than among smoking patients (Table $\mathbf{2}$, Figs. $\mathbf{1}$ and 2).

The rank analysis of variations by Kruskal-Wallis test for multiple comparisons between groups revealed statistically significant group differences in terms of lipids for patients according to the smoking status: TCH KruskalWallis test: $\mathrm{H}(2, \mathrm{~N}=234)=9.119, p=0.0105$, LDL-C Kruskal-Wallis test: $\mathrm{H}(2, \mathrm{~N}=225)=6.2615, p=0.0437$, TG Kruskal -Wallis test: $\mathrm{H}(2, \mathrm{~N}=216)=9.8485, p=0.0073$.

To study the effect of lipid-lowering therapy on the lipid profile, depending on the status of smoking, we conducted an additional analysis of the frequency of statins use in subgroups of patients and the correlation analysis.

The results of the frequency of statins use are reflected in Table 3. The proportion of patients receiving statins therapy in each group showed similar data: accordingly $59.3 \%, 60.97 \%$ and $65.2 \%$ for the group of smokers, nonsmokers and past-smokers. 


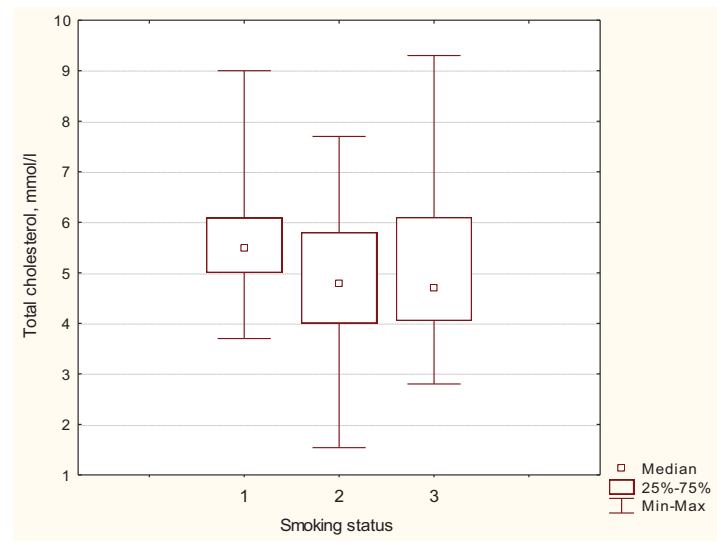

Fig. (1). Intergroup differences by TCH levels; 1 - smokers; 2 -non-smokers; 3 - past-smokers.

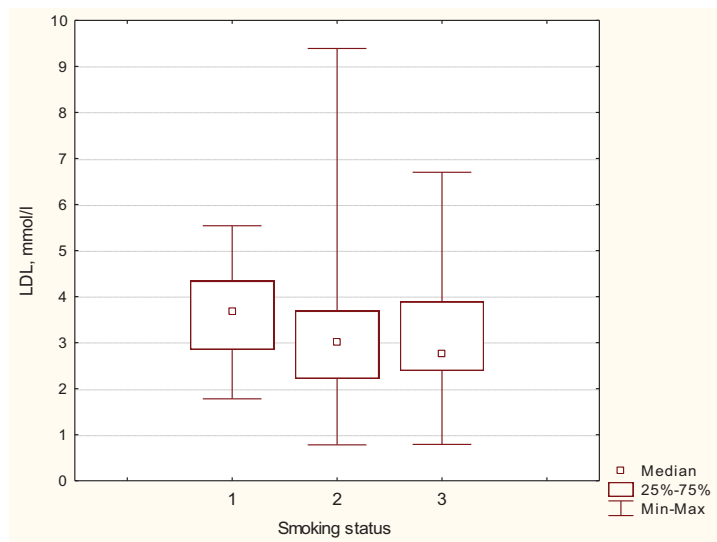

Fig. (2). Intergroup differences by LDL-C levels; 1 - Smokers; 2 - non-smokers; 3 - past-smokers.

Table 3. Comparative characteristics of patients groups by smoking status and admission of statin therapy.

\begin{tabular}{|c|c|c|c|}
\hline Patients Groups & (1) Smokers & (2) Non-Smokers & (3) Past-Smokers \\
\hline who take statins constantly & $16(59.3 \%)$ & $75(60.97 \%)$ & $30(65.2 \%)$ \\
\hline who take statins irregularly & $1(3.7 \%)$ & $16(13.01 \%)$ & $4(8.7 \%)$ \\
\hline who don't take statins & $10(37.0 \%)$ & $32(26.02 \%)$ & $12(26.1 \%)$ \\
\hline
\end{tabular}

The comparison of these groups on the basis of multiple field conjugacy tables using $\chi^{2}$ criterion was carried out to eliminate the influence of this factor on the intergroup differences.

The absence of statistically significant differences between groups was confirmed by the fact of statin therapy both for the three groups $\left(\chi^{2}=3.169, \mathrm{df}=4, p=0.529\right)$, and for the two ones when combining the group of those who do not take statins and the group of those who take them irregularly into one group in comparison with the group of patients who take statins constantly $\left(\chi^{2}=0.365, \mathrm{df}=2, p=0.833\right)$.

Dunn criterion (Q) is used for multiple comparison of samples of different size. The present criterion was used in this case to compare the groups in pairs and determine statistically significant differences between them in comparison with the control group taken for the Group 1. The results of comparison of groups based on the Dunn criterion are presented below:

- Groups 1 and 2 - for TCH Q =3.44, $p<0.01$; for LDL-C Q $=2.48, p<0.05$; for TG $\mathrm{Q}=2.99, p<0.01$.

- Group 1 and 3 - for TCH Q =2.13, $p>0.05$; for LDL-C Q $=1.98, p>0.05$; for TG $\mathrm{Q}=1.43, p>0.05$.

- Group 3 and 2 - for TCH Q $=0.66, p>0.05$; for LDL-C Q $=0.16, p>0.05$; for TG $\mathrm{Q}=1.52, p>0.05$. 
Thus, statistically significant differences in lipid profile based on the results of the analysis are ascertained for the two groups: smokers and non-smokers. These indices were lower in the last group. However, statistically significant differences were not confirmed for a group of those who gave up smoking in comparison with other groups.

Further analysis we have devoted to the study of the influence of various factors, including smoking, on the possibility of achieving target values of lipids in patients with arterial hypertension.

Logistic regression was selected for multivariate analysis. The contribution of different factors in achieving target lipid levels, the odds ratio obtaining this result and their confidence intervals were determined by this method. Results of logistic regression analysis are shown in Table 4.

Table 4. The results of logistic regression analysis: the impact of several factors on the outcome achieve target lipid levels.

\begin{tabular}{|c|c|c|c|c|c|c|c|c|}
\hline Factors & Estimate & Standard Error & Wald Statistic & Odds Ratio & Lower CL & Upper CL & $\boldsymbol{p}$-value \\
\hline Job stress & -0.03043 & 0.591548 & 0.002646 & 1.120454 & -1.18984 & 1.128986 & 0.958979 \\
\hline Physical activity & -0.10304 & 1.133120 & 0.008269 & 1.012454 & -2.32392 & 2.117835 & 0.927545 \\
\hline Overweight (BMI $\left.>25 \mathrm{~kg} / \mathrm{m}^{2}\right)$ & -0.02045 & 0.558367 & 0.001342 & 1.261436 & -1.11483 & 1.073926 & 0.970780 \\
\hline Current smoking & 2.50584 & 1.208397 & 4.300198 & $\mathbf{0 . 1 0 4 5 0}$ & 0.13743 & 4.874259 & $\mathbf{0 . 0 3 8 1 0 8}$ \\
\hline Diet & 0.60952 & 0.847502 & 0.517244 & 0.991356 & -1.05155 & 2.270595 & 0.472020 \\
\hline Statin therapy & -2.19396 & 0.718939 & 9.312643 & $\mathbf{8 . 1 7 2 0 5 0}$ & -3.60305 & -0.784864 & $\mathbf{0 . 0 0 2 2 7 6}$ \\
\hline Education level & -1.70954 & 1.367826 & 1.562054 & 0.542836 & -4.39043 & 0.971351 & 0.211365 \\
\hline Alcohol consumption & 0.38002 & 0.313639 & 1.468081 & 1.727849 & -1.18984 & 1.128986 & 0.225649 \\
\hline
\end{tabular}

Two factors had the greatest weight value and became statistically significant in this model: smoking and statin therapy. Moreover, current smoking has a negative impact and reduces the likelihood of achieving the target lipid levels (OR $0.1 ; 95 \%$ CI $[0.13,4.87] ; p=0.03)$. Statin therapy increases the chances of achieving the target lipid levels (OR $8.2 ; 95 \%$ CI $[-3.6 ;-0.078] ; p=0.002)$.

\section{DISCUSSION AND LIMITATIONS}

One should note the limitations of the conducted study: the selectivity of the surveyed group - it was not an epidemiological study. At the same time, it was the analysis of real clinical practice, examination of ordinary patients with arterial hypertension. The study cohort differs from the general Russian population according to these characteristics due to obvious circumstances - all patients included in the register were predominantly patients with arterial hypertension and associated cardiovascular diseases observed in a specialized center. In this regard, it is logical to state that they have a greater prevalence of arterial hypertension and dyslipidemia with fewer smokers $(23.5 \%$ vs $14.8 \%$ ), since doctors had to motivate them to quit smoking [13]. The feature of this study was that the distinct differences between the two groups of smokers and non-smokers were confirmed in lipid profile regardless of statin therapy.

A limitation of this study was that the period of smoking cessation has not been clearly ascertained in the group of those who gave up smoking. It is known that those who give up smoking can reach the level of never smokers by risk stratification only after a few years after giving up. The following is said on this issue in prevention programs of the World Health Organization on the basis of previous studies [14 - 16]:

1. The risk of coronary heart disease decreases twice compared to such risk of a smoker during 1 year.

2. The risk of stroke decreases to the level of risk of a non-smoking person in 5-15 years after giving up smoking.

\section{CONCLUSION}

The presence of statistically significant differences in lipid indices among patients with arterial hypertension and associated cardiovascular diseases depending on the smoking status was ascertained according to the results of this study. Significantly higher levels of lipids such as TCH, LDL-C, TG have been observed among smokers compared to non-smokers which are confirmed by the results of statistical analysis. At the same time, the level of HDL was not significantly different depending on the status of smoking in this cohort.

Logistic regression analysis showed the following: if statin therapy increases the chances to achieve target lipid levels, in the opposite of statin therapy, smoking has a negative impact and reduces the chances of achieving the desired result of treatment. 
These findings point out the need for active promotion of preventive programs for giving up smoking and indicate the expediency of a more active statin therapy aimed at reducing hyperlipidemia and the cardiovascular risk among smoking patients.

\section{LIST OF ABBREVIATIONS}

$\begin{array}{lll}\text { BMI } & = & \text { Body Mass Index } \\ \text { HDL-C } & = & \text { High-Density Lipoprotein Cholesterol } \\ \text { LDL-C } & = & \text { Low-Density Lipoprotein Cholesterol } \\ \text { NRCPM } & = & \text { National Research Center for Preventive Medicine } \\ \text { TCH } & = & \text { Total Cholesterol } \\ \text { TG } & = & \text { Triglycerides }\end{array}$

\section{ETHICS APPROVAL AND CONSENT TO PARTICIPATE}

Not applicable.

\section{HUMAN AND ANIMAL RIGHTS}

No Animals/Humans were used for studies that are base of this research.

\section{CONSENT FOR PUBLICATION}

Not applicable.

\section{CONFLICT OF INTEREST}

The authors declare no conflict of interest, financial or otherwise.

\section{ACKNOWLEDGEMENTS}

Decleared none.

\section{REFERENCES}

[1] Doonan RJ, Hausvater A, Scallan C, Mikhailidis DP, Pilote L, Daskalopoulou SS. The effect of smoking on arterial stiffness. Hypertens Res 2010; 33(5): 398-410 [http://dx.doi.org/10.1038/hr.2010.25] [PMID: 20379189]

[2] Saladini F, Benetti E, Fania C, Mos L, Casiglia E, Palatini P. Effects of smoking on central blood pressure and pressure amplification in hypertension of the young. Vasc Med 2016; 21(5): 422-8.

[http://dx.doi.org/10.1177/1358863X16647509] [PMID: 27197683]

[3] Mandraffino G, Imbalzano E, Mamone F, et al. Biglycan expression in current cigarette smokers: A possible link between active smoking and atherogenesis. Atherosclerosis 2014; 237(2): 471-9. [http://dx.doi.org/10.1016/j.atherosclerosis.2014.10.024] [PMID: 25463076]

[5] Bruckert E, Jacob N, Lamaire L, Truffert J, Percheron F, de Gennes JL. Relationship between smoking status and serum lipids in a hyperlipidemic population and analysis of possible confounding factors. Clin Chem 1992; 38(9): 1698-705. [PMID: 1526001]

[6] Reiner Z, Catapano AL, De Backer G, et al. ESC/EAS Guidelines for the management of dyslipidaemias: the Task Force for the management of dyslipidaemias of the European Society of Cardiology (ESC) and the European Atherosclerosis Society (EAS). Eur Heart J 2011; 32(14): 1769-818. [http://dx.doi.org/10.1093/eurheartj/ehr158] [PMID: 21712404]

[7] Stone NJ, Robinson JG, Lichtenstein AH, et al. 2013 ACC/AHA guideline on the treatment of blood cholesterol to reduce atherosclerotic cardiovascular risk in adults: A report of the American College of Cardiology/American Heart Association Task Force on Practice Guidelines. J Am Coll Cardiol 2014; 63(25 Pt B): 2889-934. [http://dx.doi.org/10.1016/j.jacc.2013.11.002] [PMID: 24239923]

[8] Mancia G, Fagard R, Narkiewicz K, et al. 2013 ESH/ESC Guidelines for the management of arterial hypertension: the Task Force for the management of arterial hypertension of the European Society of Hypertension (ESH) and of the European Society of Cardiology (ESC). J Hypertens 2013; 31(7): 1281-357. [http://dx.doi.org/10.1097/01.hjh.0000431740.32696.cc] [PMID: 23817082]

[9] Bišanović S, Mehić B, Sivić S. Status of lipids and the frequency diseases of cardiovascular origin in smokers according to the length period of smoking and a number of cigarettes smoked daily. Bosn J Basic Med Sci 2011; 11(1): 46-51. [http://dx.doi.org/10.17305/bjbms.2011.2623] [PMID: 21342142] 
[10] Byeon YS, Lee HS. [Relation of the blood pressure, lipids and body mass index by smoking status among adolescents]. Taehan Kanho Hakhoe Chi 2007; 37(6): 1020-6. [Article in Korean]. [http://dx.doi.org/10.4040/jkan.2007.37.6.1020] [PMID: 17992075]

[11] Słodczyk E, Szołtysek-Bołdys I, Kozar-Konieczna A, et al. Plasma lipid concentration in smoking and nonsmoking male adults treated from alcohol addiction. Przegl Lek 2013; 70(10): 805-8. [PMID: 24501800]

[12] Batic-Mujanovic O, Beganlic A, Salihefendic N, Pranjic N, Kusljugic Z. Influence of smoking on serum lipid and lipoprotein levels among family medicine patients. Med Arh 2008; 62(5-6): 264-7.

[PMID: 19469266]

[13] Muromtseva GA, Kontsevaya AV, Konstantinov VV, et al. The prevalence of risk factors for noncommunicable diseases among Russian population in 2012-2013. Results of the ESSE-RF study Cardiovascular therapy and prevention (Russian Federation) 2014; 13(6): 4-11. [in Russian].

[14] Rosenberg L, Kaufman DW, Helmrich SP, Shapiro S. The risk of myocardial infarction after quitting smoking in men under 55 years of age. N Engl J Med 1985; 313(24): 1511-4. [http://dx.doi.org/10.1056/NEJM198512123132404] [PMID: 4069159]

[15] Smokers' beliefs about the health benefits of smoking cessation: 20 U.S. communities, 1989. MMWR Morb Mortal Wkly Rep 1990; 39(38): 653-6.

[PMID: 2118979]

[16] Doll R, Peto R, Boreham J, Sutherland I. Mortality in relation to smoking: 50 years' observations on male British doctors. BMJ 2004; 328(7455): 1519-27.

[http://dx.doi.org/10.1136/bmj.38142.554479.AE] [PMID: 15213107]

\section{(C) 2018 Gaisenok et al.}

This is an open access article distributed under the terms of the Creative Commons Attribution 4.0 International Public License (CC-BY 4.0), a copy of which is available at: (https://creativecommons.org/licenses/by/4.0/legalcode). This license permits unrestricted use, distribution, and reproduction in any medium, provided the original author and source are credited. 